\title{
Design and Analysis of Pressure Vessel According to Internal Desig n Pressure and Temperature Using FEM
}

\author{
Lida Heng ${ }^{1, ~ a, ~ J o o ~ H y u n ~ P a r k, ~ b, ~ R u i ~ W a n g ~}{ }^{1, c}$, Min Soo Kim ${ }^{1, d}$, \\ Gyun Eui Yang ${ }^{2,}$, , Sang Don Mun ${ }^{1, f^{*}}$
}

${ }^{1}$ Division of Mechanical Design Engineering, Chonbuk National University, 664-14, Duckjin-dong, Duckjin-gu, Jeonju, South Korea, 561-756

${ }^{2}$ Division of Mechanical Engineering, Chonbuk National University, 664-14, Duckjin-dong, Duckjin-gu, Jeonju, Seoul, South Korea, 561-756

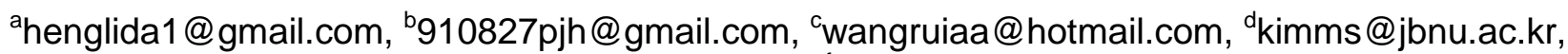
egeyang@jbnu.ac.kr, ${ }^{\dagger} \mathrm{msd@jbnu.ac.kr}$

Keywords: Pressure vessel, Finite element method (FEM), Internal design pressure, Design temperature, Equivalent stress

\begin{abstract}
The main objective of this study is to design and analyze the important components of pressure vessel according to the internal design pressure and temperature by using finite element method. A pressure vessel is a closed container designed to hold gases or liquids at a pressure substantially different from ambient pressure. They have been widely used in a variety of applications such as, in chemical industries, in thermal and nuclear power plants, in food industries, and aircraft industry. Therefore, the pressure vessels are to be designed carefully to avoid the failures which are mostly stress dependent. The requirements of stress analysis are needed to avoid the failure and the fatal accidents of pressure vessel. In this study, the important components of pressure vessel such as a blind flange, a shell flange, some eye bolts, a drain pipe, a drain pipe flange, and some junction areas of pressure vessel were specifically designed with reliable materials in accordance with ASME Code. The finite element modeling, the evaluation of equivalent stress, and the stress classification lines (SCLs) for specified points were performed using a Midas NFX program based on the finite element method (FEM). The stress analysis for the design condition involving internal pressure and thermal load has been evaluated in accordance with ASME boiler and pressure vessel code. The conclusion is that the analysis results for the normal operating condition satisfied allowable limits. Therefore, the current design of the pressure vessel has enough strength under the design load conditions.
\end{abstract}

\section{Introduction}

Pressure vessel is a closed container designed to hold gases or liquids at a pressure substantially different from the ambient pressure. They are used as reactor, convertor, regenerator or splitter [1]. They have been widely used in a variety of applications such as, in chemical industries, in thermal and nuclear power plants, in food industries, and aircraft industries [2, 3]. The pressure vessels are designed to store the transmit liquids, reactive fluids, vapor, and gases under pressure in general. Thus, these pressure vessels must be designed carefully to avoid the failures or to reduce the risk and likelihood of such accidents occurring. Furthermore, the stress analysis of pressure vessel is required to ensure that the pressure vessel has ability to withstand the internal pressure and temperature or not. In previous work, many accidents were caused by the pressure vessel. Bulk transporter [4] reported that the national board of boiler and pressure vessel inspectors recorded the number of accidents involving pressure vessels at an increase of $24 \%$ over the course of a year between 1999 to 2000. The number of fatalities as a direct result of boiler and pressure vessel accidents has been recorded as 127 over the past 10 years [5]. In this work, in order to overcome the accidents caused by pressure vessel, some important components of pressure vessel such as a blind flange, a shell flange, some eye bolts, a drain pipe and a drain pipe flange, and junction areas were specifically designed with the reliable materials in accordance with ASME Code and analyze using 
finite element method (FEM). The main purpose of this analysis is to evaluate the stability of the stress in blind flange, shell flange, drain pipe, drain pipe flange, and junction area of pressure vessel. The finite element modeling and the evaluation for specified points are performed using a Midas NFX program based on the Finite Element Method (FEM). The stress analysis for the design condition involving the internal pressures and the thermal load has been evaluated in accordance with ASME Boiler and Pressure Vessel Code. The analysis were performed under design load condition to determine the comparison to acceptance criteria and the suitability of a component based on the design requirements for application of the design by analysis methodology described in ASME Sec. VIII Part 5 for stress evaluation, which are provided as part of the design for an accurate stress analysis including validation of all results.

\section{Design Criteria}

Modeling of Pressure Vessel. Fig. 1 shows three dimensional model of pressure vessel, which was modelled in Catia V5R18. Two inlet ports from where the gas enters the pressure vessel have been provided at the head of pressure vessel. The drain pipe has been provided at the bottom of pressure vessel for draining out the fluid from the vessel. The blind flange and shell flange have been provided at the end of pressure vessel. In this work, some important components of pressure vessel such as a blind flange, a shell flange, some eye bolts, a drain pipe and a drain pipe flange were specifically designed with reliable materials in accordance with ASME Code. The analysis has done with only 1/4 part of the pressure vessel components. Fig. 2 and Fig. 3 show the full model of blind flange with shell flange and drain pipe with drain pipe flange, respectively. Table 1 shows the dimensions of pressure vessel components.

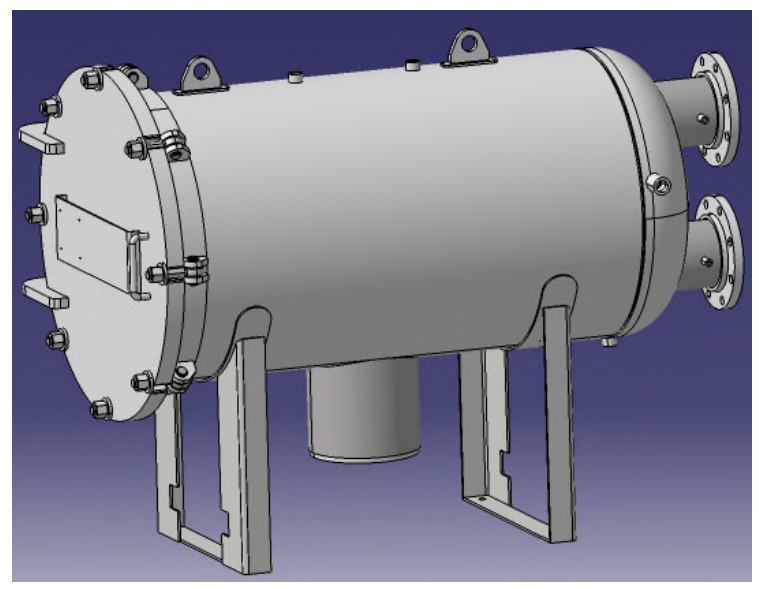

Fig. 1 Full model of pressure vessel.

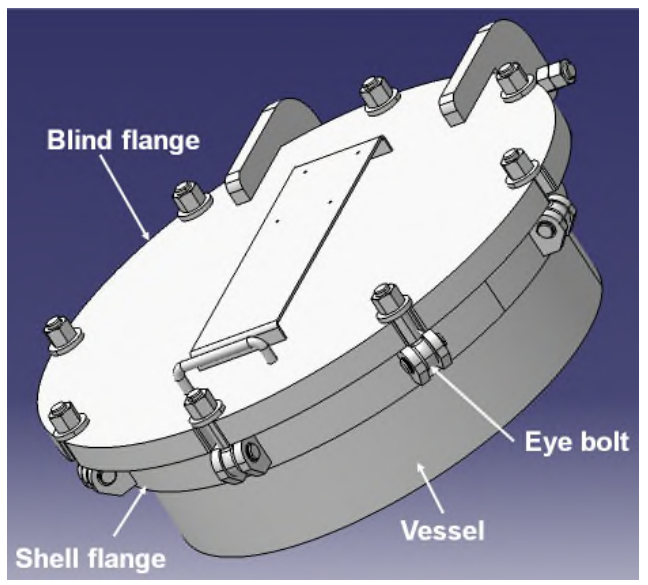

Fig. 2 Full model of blind flange with shell flange.

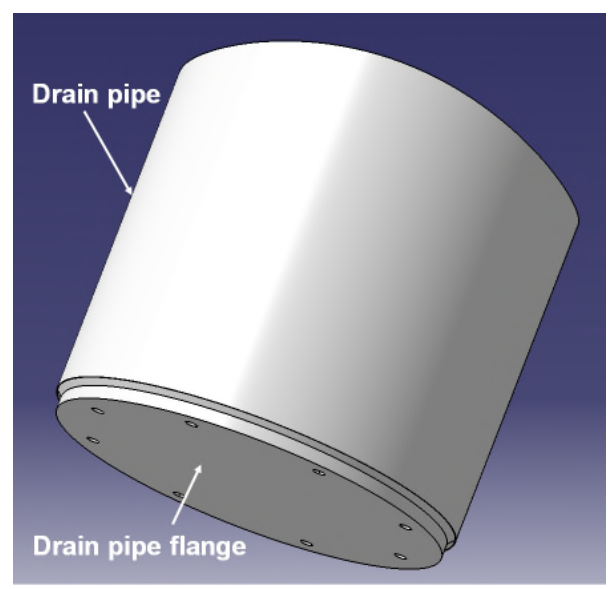

Fig. 3 Full model of drain pipe with drain pipe flange. 
Table 1. Dimensions of the pressure vessel components.

\begin{tabular}{|c|c|c|}
\hline Sr. No. & Components & Remark \\
\hline 1 & Blind flange & $\varnothing 870-\mathrm{t} 44(\mathrm{~mm})$ \\
\hline 2 & Shell flange & $\varnothing 762-\mathrm{t} 26.5(\mathrm{~mm})$ \\
\hline 3 & Drain pipe & $\varnothing 273-\mathrm{t} 8.5(\mathrm{~mm})$ \\
\hline 4 & Drain pipe flange & $\varnothing 264-\mathrm{t} 20(\mathrm{~mm})$ \\
\hline 5 & Eye bolt & M24-120L $(\mathrm{mm})$ \\
\hline
\end{tabular}

Design Conditions. The design criteria for pressure vessel are provided by the user's design specification and in accordance with ASME Boiler and Pressure Vessel Code. There are three parameters were used in the stress analysis of pressure vessel like, pressure, temperature, and corrosion allowance. The pressure used in the design of a vessel is called design pressure. It is recommended to design a pressure vessel and its parts for a higher pressure than the operating pressure. A design pressure must be higher than the operating pressure with 10 percent, whichever is the greater, will satisfy the requirement. The design temperature is very important because it is the temperature that will be maintained in the metal part of the vessel being considered for the specified operation of the vessel. For most vessels, it is the temperature that corresponds to the design pressure. Design temperature for vessels under the external pressure shall not exceed the maximum temperatures. Corrosion occurring over the life of a vessel is catered for by a corrosion allowance, the design value of which depends upon the vessel duty and the corrosiveness of its content. Table 2 shows the values of pressure, temperature and corrosion allowance for this analysis

Table 2. Design conditions.

\begin{tabular}{|c|c|}
\hline & Shell side \\
\hline Design pressure $(\mathrm{MPa})$ & 4.0 \\
\hline Design temperature $\left({ }^{\circ} \mathrm{C}\right)$ & $-29 \sim 121$ \\
\hline Corrosion allowance $(\mathrm{mm})$ & 0.0 \\
\hline
\end{tabular}

Material Selection and Mechanical Material Properties. The selection of materials is important activity that is essential for structural design. The selection of material for pressure vessel depends on a number of factors such as operating pressure, operating temperature, operating medium, regulations in force in the country of the plant user concerned and manufacturing possibilities [6]. The selection of material of the pressure vessel components take into account the suitability of the materials with maximum working pressure and fabrication process. Table 3 shows the material selection used for pressure vessel components. Table 4 shows the mechanical material properties. The materials properties data in this model are taken from ASME Sec. II, Part D -Properties.

Table 3. Material selection used for pressure vessel components.

\begin{tabular}{|c|c|c|}
\hline Sr. No. & Components & Material \\
\hline 1 & Blind flange & SA-240-304 \\
\hline 2 & Shell flange & SA-240-304 \\
\hline 3 & Drain pipe flange & SA-240-304 \\
\hline 4 & Drain pipe & SA-312-304 \\
\hline 5 & Eye bolt & SA-193-B7 \\
\hline
\end{tabular}

Table 4. Mechanical material properties.

\begin{tabular}{|c|c|c|c|}
\hline Materials & SA-240-304 & SA-193-B7 & SA-312-304 \\
\hline Components & $\begin{array}{c}\text { Blind flange, Shell flange, } \\
\text { Drain pipe flange }\end{array}$ & Eye bolt & 193,000 \\
\hline Elastic modulus $(\mathrm{MPa})$ & 193,000 & 205,000 & 860 \\
\hline Tensile Strength $(\mathrm{MPa})$ & $520-720$ & 515 & 0.3 \\
\hline Poisson's ratio & 0.31 & 0.29 & \\
\hline
\end{tabular}


Allowable Stresses. The allowable stresses for the materials of the blind flange and other components are taken from the ASME Code as shown below. Table 5 shows allowable stresses at design temperature.

Table 5. Allowable stresses at design temperature.

\begin{tabular}{|c|c|c|c|}
\hline Materials & SA-240-304 & SA-193-B7 & SA-312-304 \\
\hline Components & $\begin{array}{c}\text { Blind flange, Shell flange, Vessel, } \\
\text { Drain pipe flange }\end{array}$ & Eye bolt & Drain pipe \\
\hline Design Temperature $\left({ }^{\circ} \mathrm{C}\right)$ & $-29 \sim 121$ & $-29 \sim 121$ & $-29 \sim 121$ \\
\hline Allowable stress $(\mathrm{MPa})$ & 138.0 & 172.0 & 138.0 \\
\hline
\end{tabular}

\section{Finite Element Analysis}

Fig. 4 and Fig. 5 show the 1/4 FE model of bling flange with shell flange and drain pipe with drain pipe flange, respectively. The use of finite element methods to design and analyze pressure vessels is a relatively recent development in the overall historical perspective of the ASME Code. The finite element technique has been applied in the analysis of a variety of pressure vessel problems [7]. In the finite element method, a structure is broken down into many small simple blocks or elements. In this work, the finite element models of blind flange and other components have been created by meshing the geometry with 3D solid elements using a Midas NFX program. Analysis has done with only 1/4 part of the components with appropriate boundary conditions.

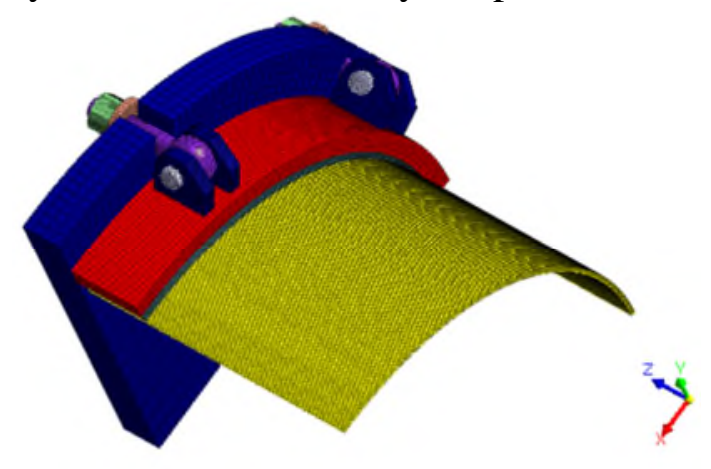

Fig. 4 1/4 FE model of blind flange with shell flange.

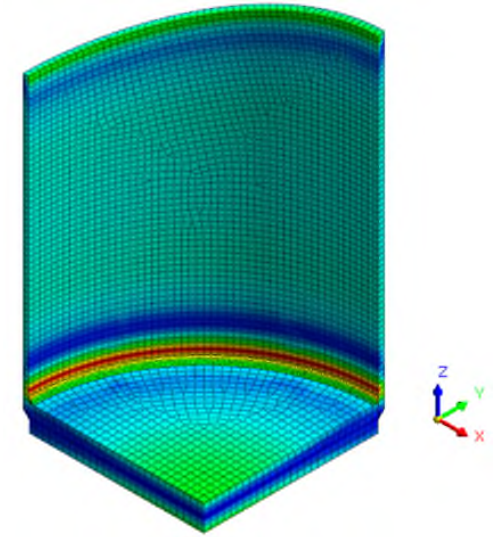

Fig. 5 1/4 FE model of drain pipe with drain pipe flange.

Boundary and Loading Conditions. The boundary conditions of blind flange with shell flange of pressure vessel are shown in Fig 6 and Fig. 7, respectively. The internal pressure is $4 \mathrm{MPa}$ was applied to the inside of pressure vessel. The pressure load which is pressed inside the pressure vessel is shown in Fig. 10 and Fig. 11, respectively. Fig. 8 and Fig. 9 show the boundary conditions of drain pipe with drain pipe flange.

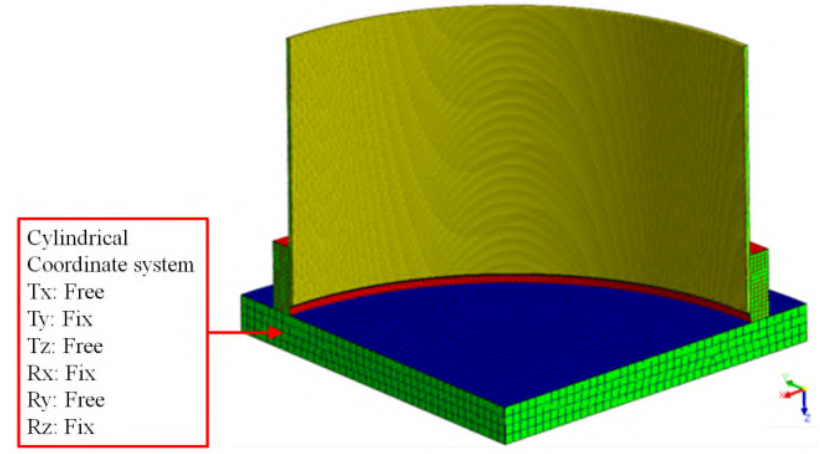

Fig. 6 Boundary condition of $1 / 4$ blind flange.

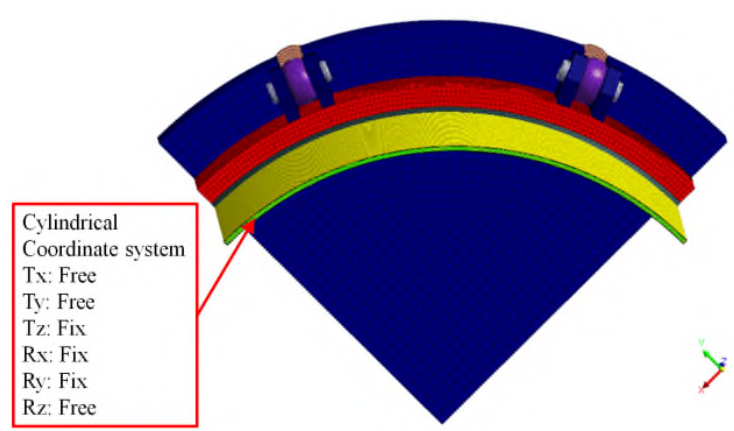

Fig. 7 Boundary condition of 1/4 blind flange. 


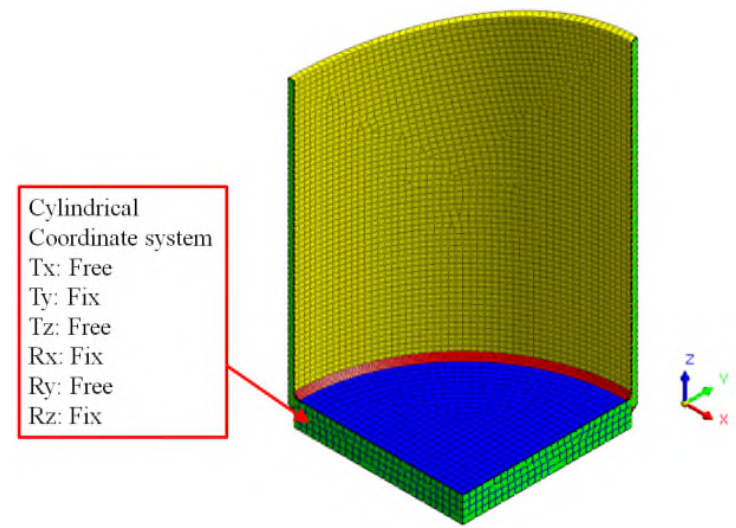

Fig. 8 Boundary condition of 1/4 drain pipe.

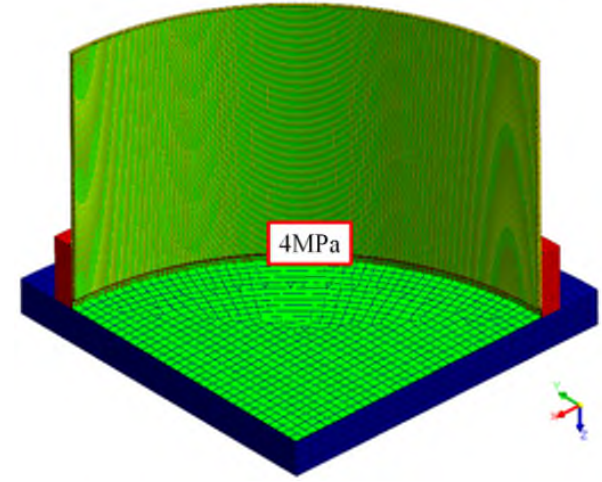

Fig. 10 Loading condition of blind flange with shell flange.

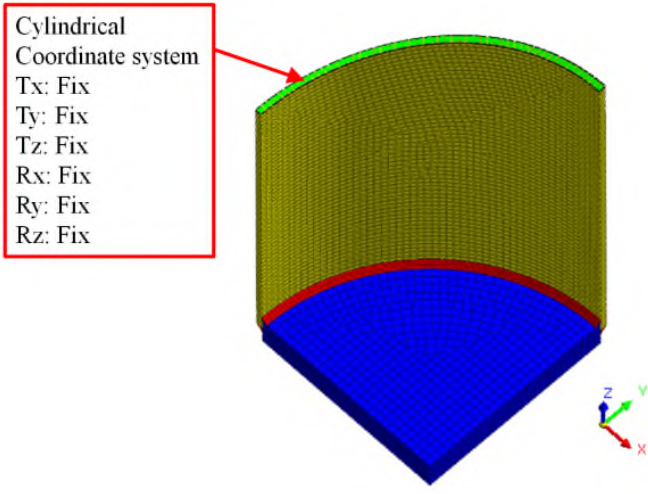

Fig. 9 Boundary condition of $1 / 4$ drain pipe.

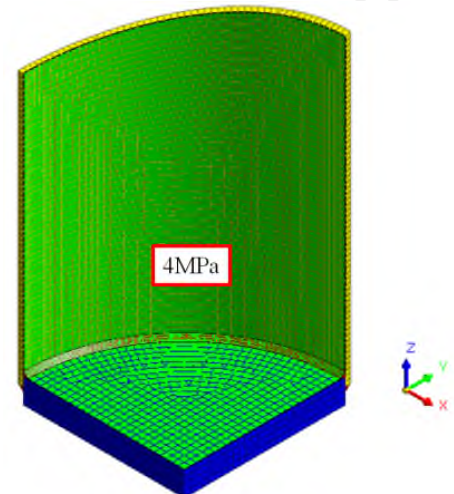

Fig. 11 Loading condition of drain pipe with drain pipe flange.

\section{Analysis Results}

SCLs and Stress distributions. The stress analysis is based on the radial and circumference stress calculated for the blind flange, shell flange, eye bolt, drain pipe, drain pipe flange, and junction area of pressure vessel under the design condition. The stress equivalent of blind flange, shell flange and eye bolt, drain pipe, and drain pipe flange is calculated in accordance with following step based on ASME SEC VIII, Div.1 (Ed. 2013).

(1) Primary general membrane stress $\left(\mathrm{P}_{\mathrm{m}}\right)<1.0 \mathrm{k}$

(2) Primary local membrane stress $\left(\mathrm{P}_{\mathrm{L}}\right)<1.5 \mathrm{kS}$

(3) Primary local membrane + Bending stress $\left(\mathrm{P}_{\mathrm{L}}+\mathrm{P}_{\mathrm{b}}\right)<1.5 \mathrm{kS}$

(4) Primary plus secondary stress $\left(\mathrm{P}_{\mathrm{L}}+\mathrm{P}_{\mathrm{b}}+\mathrm{Q}\right)<3 \mathrm{~S}$ where, $\mathrm{k}$ : 1.0, $\mathrm{S}=$ Maximum allowable stress at design temperature.

Stress classification lines (SCLs) were plotted near the junction area and the intensity of equivalent stresses is observed across the junctin area of pressure vessel. Stress classification lines are established as shown in Fig. 12 and Fig. 13. The results under the design condition are organized in Table 6 and Table 7. The design of pressure vessel can be safe and can be put to use unless the actual stress is lesser than the allowable stress of the material. As shown in Table 6 and Table 7 that the actual stress evaluation of SCL1, SCL2, and SCL3 is lesser than the allowable stress of material. Therefore, this current design of the pressure vessel is safe and can be put to use.

Table 6. Stress classification lines of blind flange and shell flange.

\begin{tabular}{|c|c|c|c|c|c|}
\hline \multirow{2}{*}{ SCL } & \multicolumn{2}{|c|}{$\mathrm{P}_{\mathrm{L}}<(1.5 \times \mathrm{KS})$} & \multicolumn{2}{|c|}{$\mathrm{P}_{\mathrm{L}}+\mathrm{P}_{\mathrm{b}}+\mathrm{Q}<(3 \times \mathrm{S})$} & \multirow{2}{*}{ Result } \\
\cline { 2 - 5 } & Actual & Allowable & Actual & Allowable & \\
\hline SCL1 & 149.37 & 207.0 & 375.47 & 414.0 & OK \\
\hline SCL2 & 138.99 & 207.0 & 250.88 & 414.0 & OK \\
\hline SCL3 & 99.49 & 207.0 & 332.86 & 414.0 & OK \\
\hline
\end{tabular}


Table 7. Stress classification lines of drain pipe, drain pipe flange.

\begin{tabular}{|c|c|c|c|c|c|}
\hline \multirow{2}{*}{ SCL } & \multicolumn{2}{|c|}{$\mathrm{P}_{\mathrm{L}}<(1.5 \times \mathrm{S})$} & \multicolumn{2}{c|}{$\mathrm{P}_{\mathrm{L}}+\mathrm{P}_{\mathrm{b}}+\mathrm{Q}<(3 \times \mathrm{S})$} & \multirow{2}{*}{ Result } \\
\cline { 2 - 5 } & Actual & Allowable & Actual & Allowable & \\
\hline SCL1 & 68.73 & 207.0 & 340.21 & 414.0 & OK \\
\hline SCL2 & 58.34 & 207.0 & 279.64 & 414.0 & OK \\
\hline SCL3 & 26.27 & 207.0 & 70.39 & 414.0 & OK \\
\hline
\end{tabular}

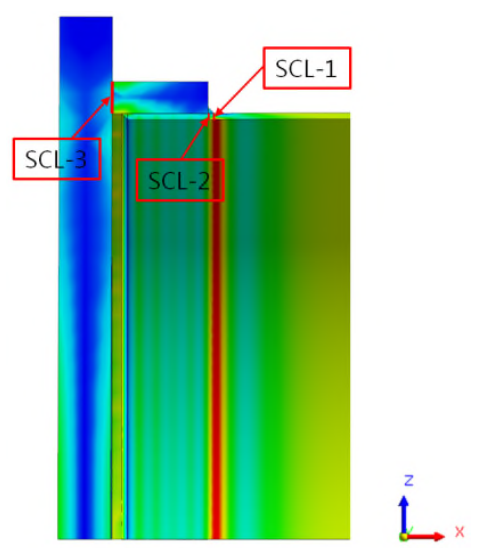

Fig. 12 SCLs of blind flange and shell flange.

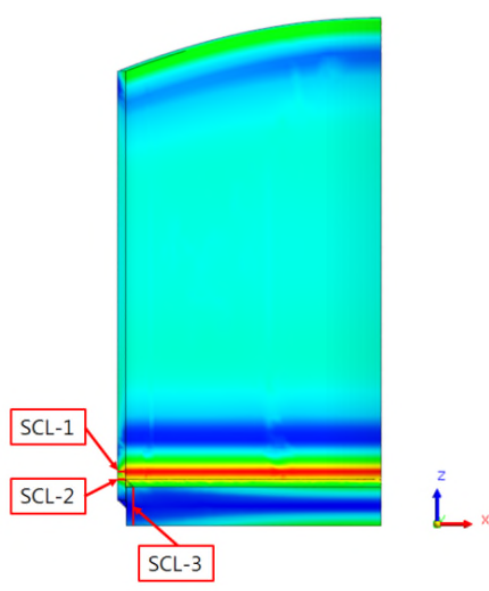

Fig. 13 SCLs of sump flang.

The results from the analysis have been processed to determine stress in the critically stressed regions of blind flange and other components under the design condition as shown in table 8. Fig. 14 shows the equivalent stress of blind flange without eye bolt. The minimum and maximum equivalent stress of blind flange obtained by Mixdas program was 4.170MPa, and 188.990Mpa, respectively. The design of pressure vessel can be safe and can be put to use unless the equivalent stress is lesser than the allowable stress of the material. As shown in Table 8 that the minimum and maximum equivalent stress of pressure vessel components are lesser than the allowable stress. Therefore, this current design of the pressure vessel is safe and can be put to use. Fig. 15 shows the equivalent stress of shell flange without eye bolt. The minimum and maximum equivalent stress of shell flange obtained by Mixdas program was 19.646MPa, and 271.624Mpa, respectively. Fig. 16 shows the equivalent stress of eye bolt. The minimum and maximum equivalent stress of eye bolt was obtained to be $2.143 \mathrm{MPa}$, and 257.007Mpa, respectively. Fig. 17 and Fig. 18 show the equivalent stress of drain pipe and drain pipe flange, respectively. The minimum and maximum equivalent stress of drain pipe was $25.107 \mathrm{MPa}$, and $351.556 \mathrm{MPa}$, respectively. The minimum and maximum equivalent stress of draing pipe flange was $8.650 \mathrm{MPa}$, and $182.863 \mathrm{MPa}$, respectively.

Table 8. Allowable stresses at design temperature.

\begin{tabular}{|c|c|c|c|c|c|}
\hline \multirow{2}{*}{ Components } & \multicolumn{2}{|c|}{$\begin{array}{c}\text { Equivalent } \\
\text { Stress[MPa] }\end{array}$} & \multirow{2}{*}{ Allowable Value } & Stress Categories & \multirow{2}{*}{ Result } \\
\cline { 2 - 3 } & Min. & Max. & & & \\
\hline Blind flange & 4.170 & 188.990 & 414 & $\left(\mathrm{P}_{\mathrm{L}}+\mathrm{P}_{\mathrm{b}}+\mathrm{Q}\right)<(3 \times \mathrm{S})$ & $\mathrm{OK}$ \\
\hline Shell flange & 19.646 & 271.624 & 414 & $\left(\mathrm{P}_{\mathrm{L}}+\mathrm{P}_{\mathrm{b}}+\mathrm{Q}\right)<(3 \times \mathrm{S})$ & $\mathrm{OK}$ \\
\hline Eye bolt & 2.143 & 257.007 & 516 & $\left(\mathrm{P}_{\mathrm{L}}+\mathrm{P}_{\mathrm{b}}+\mathrm{Q}\right)<(3 \times \mathrm{S})$ & $\mathrm{OK}$ \\
\hline Drain pipe & 25.107 & 351.556 & 414 & $\left(\mathrm{P}_{\mathrm{L}}+\mathrm{P}_{\mathrm{b}}+\mathrm{Q}\right)<(3 \times \mathrm{S})$ & $\mathrm{OK}$ \\
\hline Drain pipe flange & 8.650 & 182.863 & 414 & $\left(\mathrm{P}_{\mathrm{L}}+\mathrm{P}_{\mathrm{b}}+\mathrm{Q}\right)<(3 \times \mathrm{S})$ & $\mathrm{OK}$ \\
\hline
\end{tabular}




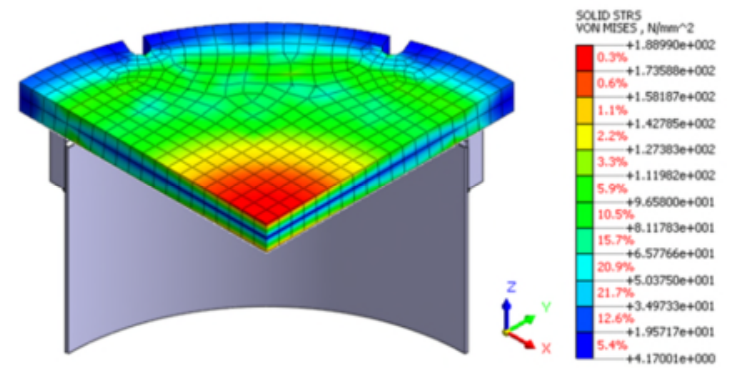

Fig. 14 Stress distribution of blind flange without eye bolt, Isotropic view.

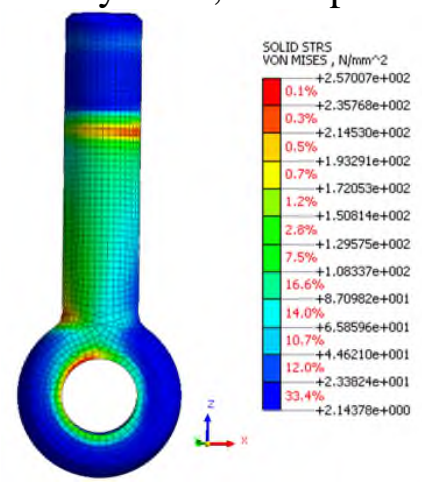

Fig. 16 Stress distribution of eye bolt, Isotropic view.

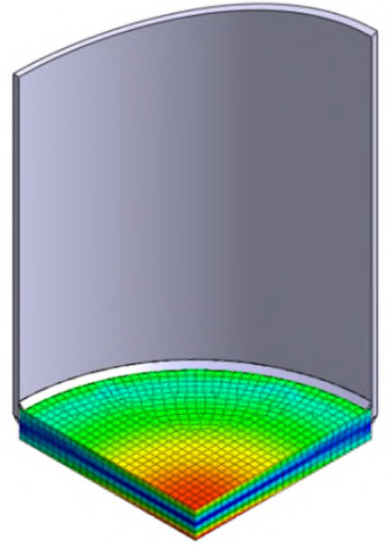

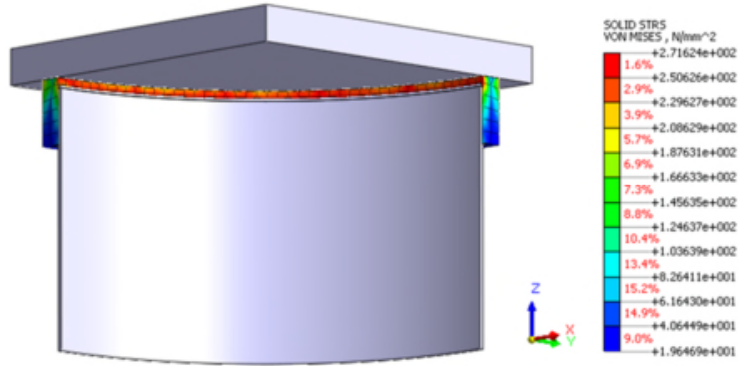

Fig. 15 Stress distribution of shell flange without bolt, Isotropic view.

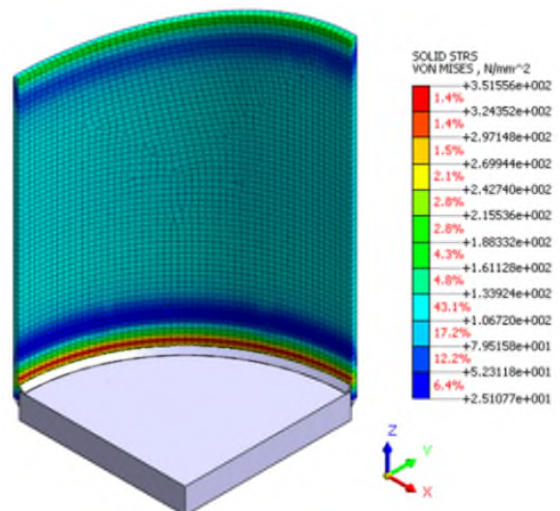

Fig. 17 Stress distribution of drain pipe, Isotropic view.

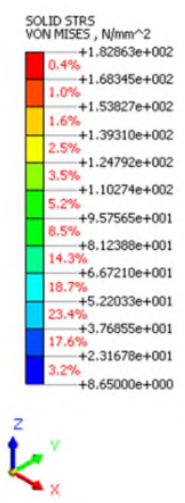

Fig. 18 Stress distribution of drain pipe flange, Isotropic view.

\section{Conclusions}

The result of this study can be summarized as follows:

(1) Various parameters of pressure vessel such as the internal design pressure, the design temperature, and the component dimension are designed in accordance with ASME boiler and pressure vessel code (ASME SEC VIII, Div.1 Ed. 2013).

(2) The evaluation for blind flange, shell flange, eye boil, drain pipe, drain pipe flange, and junction area of pressure vessel has been performed using FEA and methodology of ASME SEC VIII, Div.1 (Ed. 2013) and carried out under the prescribed specific load conditions.

(3) The stress equivalent and stress classification lines of pressure vessel components are lesser than the allowable stress of the material.

(4) The analysis results for the normal operating condition satisfied allowable limits. Therefore, current design of the blind flange, shell flange, and eye bolt has enough strength under the design load conditions. 


\section{Acknowledgment}

This work was supported by a research program of Korean government projects (Research Project No. 20150930-C3-002)

\section{References}

[1] A. Palekar, P. Kompelli, N. Mayekar, A. Shembekar, R. Kurane, R. Mahatale, S. Bharadwaj, Study and Design of Shell of Multi Wall Pressure Vessel, Int. J. Tech. Res. Appl. 4 (2016) 333-340.

[2] A. H. Shivananjappa, C. N. Nataraj, Computation of Thermal Stresses in Pressure Vessel Using Finite Element Analysis, ICAER, 2011.

[3] M. Kumar, S. K. Moulick, Comparative Stress Analysis of Elliptical and Cylindrical Pressure Vessel with and Without Autofrettage Consideration Using Finite Element Method, Int. J. Adv. Eng. Res. Studies/IV/II, (2015) 189-195.

[4] B. Transporter, Boiler, Pressure Vessel Accidents Increase, Bulk Transporter, 2009.

[5] Boiler Accident Report, To Err Is Human, 2002.

[6] P. H. Huppertz, I. A. Retter, Selection of Materials for Pressure Vessels and Chemical Plants, Mater. Sci. Eng. Tech. 11 (1980) 124-133.

[7] R. L. Davis, H. D. Keith, Finite-Element Analysis of Pressure Vessels, J. Basic Eng. 94 (2010) 401-405. 